\title{
Snapshot
}

\section{Stab in the dark}
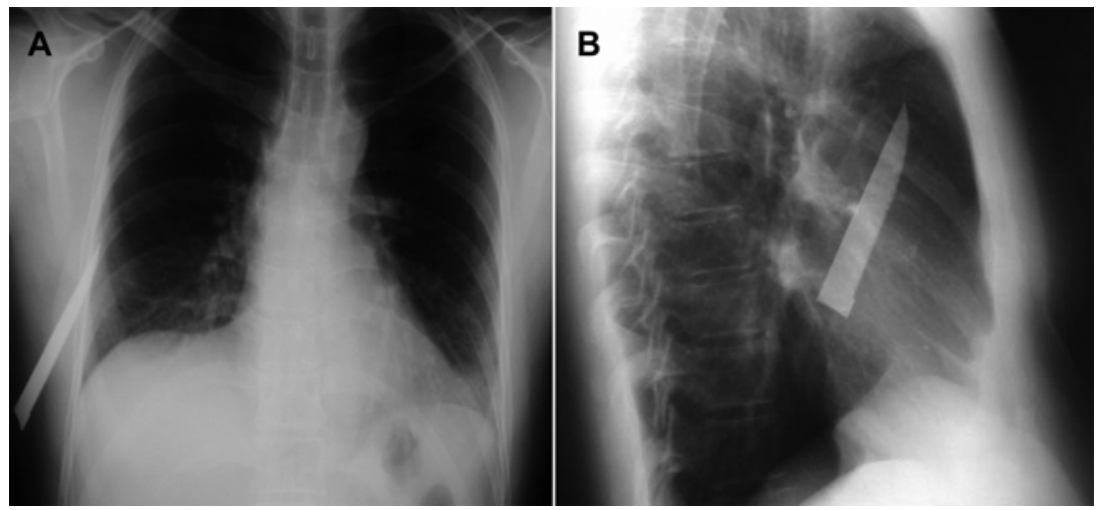

A 55-year-old man suffered a thoracic knife wound during an assault. The wound was sutured by a general practitioner. Five days later, the patient re-presented to another medical centre with chest pains after travelling on two Australian domestic flights, including one for which airport security required him to undergo screening with a metal detector.

Chest $\mathrm{x}$-rays showed a 13 -cm steak-knife blade, with no handle, lodged deep within the chest wall muscle, but not perforating the pleura (Figure, A, postero- anterior view, and B, lateral view). The blade was removed surgically.

This case highlights the need for thorough investigation of thoracic stab wounds.

Martin R Brown Cardiologist

Prince Charles Hospital, Brisbane, QLD.

martin_brown@health.qld.gov.au

doi: 10.5694/mjall.10857 